\title{
A novel microemulsion-based isotonic perfusate modulated by Ringer's solution for improved microdialysis recovery of liposoluble substances
}

\author{
Yong-Tai Zhang, Zhi Wang, Li-Na Shen, Yan-Yan Li, Ze-Hui He, Qing Xia and Nian-Ping Feng*
}

\begin{abstract}
Background: Microdialysis is promising technique for dynamic microbiochemical sampling from tissues. However, the application of typical aqueous perfusates to liposoluble substances is limited. In this study, a novel microemulsion (ME)-based isotonic perfusate (RS-ME) was prepared to improve the recovery of liposoluble components using microdialysis probes.

Results: Based on pseudo-ternary phase diagrams and comparisons of the ME area, Kolliphor ${ }^{\circledR}$ EL and Transcutol ${ }^{\circledR} \mathrm{P}$ were selected as the surfactant and co-surfactant, respectively, with a weight ratio $(\mathrm{Km})$ of 2:1 and ethyl oleate as the oil phase. The ME was mixed with Ringer's solution at a 1:6 ratio ( $\mathrm{V} / \mathrm{V})$ to obtain the isotonic RS-ME. The droplet size distribution of the ME in RS-ME was $78.3 \pm 9.2 \mathrm{~nm}$, with a zeta potential of $-3.5 \pm 0.3 \mathrm{mV}$. By microdialysis perfusion, RS-ME achieved higher recovery rates of the poorly water-soluble compounds evodiamine (EVO) and ruthenium (RUT), i.e., $58.36 \pm 0.57 \%$ and $49.40 \pm 0.57 \%$, respectively, than those of $20 \%$ (V/V) PEG 400 Ringer's solution (RS-PEG) and 10\% ( $/ \mathrm{v}$ ) ethanol Ringer's solution (RS-EtOH). In vivo microdialysis experiments confirmed that RS-ME captured EVO and RUT molecules around the dialysis membrane more efficiently and exhibited less spreading than RS-PEG and RS-EtOH.

Conclusions: Owing to the nanosized droplets formed by lipid components in the RS-ME and the limited dispersion out of the dialysis membrane, we obtained good biocompatibility and reliable dialysis results, without affecting the tissue microenvironment. As a novel perfusate, RS-ME provides an easy and reliable approach to the microdialysis sampling of fat-soluble components.
\end{abstract}

Keywords: Microdialysis, Microemulsion, Biocompatibility, Nanocarrier, Solubilization

\section{Background}

Microdialysis is a sampling technology for assaying biochemical substances in extracellular liquids in vivo [1]. After implanting a probe into the body, a micro-perfusion pump drives a perfusate flow through a dialysis membrane to dissolve small molecules around the target tissue via a concentration gradient between the inside and outside of probes, thereby enabling effective sampling from the living tissue [2]. Common perfusates

\footnotetext{
*Correspondence: npfeng@hotmail.com
}

Department of Pharmaceutical Sciences, Shanghai University

of Traditional Chinese Medicine, Shanghai 201203, People's Republic of China include normal saline, phosphate buffer, Ringer's solution, and citrate glucose anticoagulant solution; the composition of ion components, $\mathrm{pH}$ value, osmotic pressure, and ionic strength of the perfusate should be similar to those of the internal environment of the sampling site [3, 4]. Aqueous perfusates limit microdialysis to the detection of water-soluble components. In particular, using an aqueous perfusate, it is difficult to effectively dissolve fat-soluble components, resulting in low probe recovery, difficulty in detection, and large experimental error [5]. However, fat-soluble active ingredients, including pharmaceutical agents, account for a considerable proportion of biologically active substances. To increase the recovery

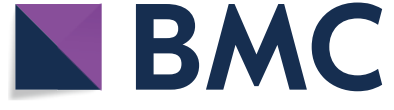

(c) The Author(s) 2018. This article is distributed under the terms of the Creative Commons Attribution 4.0 International License (http://creativecommons.org/licenses/by/4.0/), which permits unrestricted use, distribution, and reproduction in any medium, provided you give appropriate credit to the original author(s) and the source, provide a link to the Creative Commons license, and indicate if changes were made. The Creative Commons Public Domain Dedication waiver (http://creativecommons.org/ publicdomain/zero/1.0/) applies to the data made available in this article, unless otherwise stated. 
of fat-soluble components, macromolecular substances, such as transporters or cyclodextrins, have been added to the perfusate, but the former is expensive with poor stability and the latter increases the viscosity of the system $[6,7]$. In addition, these macromolecules may block the dialysis membrane pores during long-term dialysis, which in turn reduces the dialysis efficiency. Water-miscible organic solvents, such as short-chain alcohols, are also used in perfusates, but they may diffuse into the surrounding tissues through the dialysis membrane, changing the drug distribution around the probes and reducing the reliability of test results [8]. These solvents may also cause tissue irritation.

A microemulsion is a colloidal dispersion system in which emulsion droplets of $10-100 \mathrm{~nm}$ are dispersed in a mutually insoluble liquid to form a thermodynamically stable, isotropic, low-viscosity, and transparent solution [9]. An oil-in-water $(\mathrm{O} / \mathrm{W})$ microemulsion is widely used to improve the solubility of hydrophobic drugs [10]. Since the microemulsion is in a liquid state, fat-soluble molecules outside the $\mathrm{O} / \mathrm{W}$ microemulsion droplets can diffuse through the oil-water interface into the oil phase core within the droplet, thus showing a strong capacity for the extraction of fat-soluble ingredients [11]. Therefore, in addition to being carriers for fat-soluble drugs, $\mathrm{O} / \mathrm{W}$ microemulsions are used as solvents for the extraction various fat-soluble substances [12,13].

Owing to the excellent properties of water-in-oil $(\mathrm{O} / \mathrm{W})$ microemulsions, they are suitable perfusates for the microdialysis detection of fat-soluble ingredients. In this study, an isotonic $\mathrm{O} / \mathrm{W}$ microemulsion supplemented with Ringer's solution was formulated as a novel perfusate, and the water-insoluble drugs evodiamine (EVO) and rutaecarpine (RUT) were used as models to evaluate stability, safety, and probe recovery. The feasibility of the Ringer's solution-adjusted microemulsion (RS$\mathrm{ME}$ ) as a novel perfusate for the microdialysis sampling of fat-soluble ingredients was systematically evaluated.

\section{Results and discussion}

Preparation and stability of the novel microemulsion-based perfusate

The microemulsion consisted of four components: oil, water, a surfactant, and a co-surfactant [14]. Ethyl oleate with stable physicochemical properties was selected as the oil phase. Ethyl oleate is a suitable solvent for steroids and other lipophilic drugs, and its properties are similar to those of almond oil and peanut oil. However, ethyl oleate is less viscous and more easily absorbed by the body than fatty oils. It is used as a solvent for subcutaneous and intramuscular injections and as a structural component of biodegradable microcapsules for subdermal implantation and cyclosporine microemulsions [15].
Ethyl oleate has low toxicity and causes minimal tissue irritation. There are no reports of ethyl oleate-induced muscle stimulation [16]. Our previous studies have confirmed that ethyl oleate has good solubilization capacities for EVO and RUT, which is beneficial for microdialysis probe recovery [17].

To prepare the novel perfusate, Ringer's solution was used to form an isotonic solution; the prepared microemulsion must withstand the dilution of a large volume of Ringer's solution, without demulsification. Surfactants are critical for the formation of microemulsions. Nonionic surfactants are less toxic than ionic surfactants, have a low critical micelle concentration and strong emulsification ability, and are not substantially affected by changes in ionic strength and $\mathrm{pH}$ [18]. Therefore, they are frequently used in microemulsions, followed by amphiphilic surfactants and anionic surfactants, while Tween and polyoxyethylene alkyl castor oil are commonly used in nonionic surfactants $[19,20]$. In our study, Polyethylene glycol (PEG)-35 castor oil (Kolliphor ${ }^{\circledR}$ $\mathrm{EL}$ ) and Tween 80 were used as surfactants to prepare microemulsions, and Diethylene glycol monoethyl ether (Transcutol ${ }^{\circledR}$ P) and polyethylene glycol (PEG) 400 were used as co-surfactants to compare the $\mathrm{O} / \mathrm{W}$ microemulsion-forming regions by plotting pseudo-ternary phase diagrams. The surfactant and the co-surfactant were uniformly mixed according to a certain weight ratio $(\mathrm{Km})$ to prepare a mixed surfactant. Mixtures of the oil phase (ethyl oleate) and the mixed surfactant with mass ratios of 1:9, 2:8, 3:7, 4:6, 5:5, 6:4, 7:3, 8:2, and 9:1 were prepared. Water was added dropwise with magnetic stirring. The amounts of water from clarification to turbidity and from turbidity to clarification were recorded, and a pseudo-ternary phase diagram was drawn according to the amounts of oil, water, and mixed surfactants using Origin 8.0 software. Figure 1 shows the $\mathrm{O} / \mathrm{W}$ microemulsion region in the pseudo-ternary phase diagram. For the same $\mathrm{Km}$ value (1:1), using Kolliphor ${ }^{\circledR} \mathrm{EL}$ and Transcutol ${ }^{\circledR} \mathrm{P}$ as the surfactant and co-surfactant, respectively, the microemulsion region was significantly greater than that for Tween 80 as the surfactant and PEG 400 as the co-surfactant. Kolliphor ${ }^{\circledR}$ EL has a very low critical micelle concentration of only $0.009 \%$, while Tween 80 has a higher critical micelle concentration of $0.01 \%$, indicating that the former has stronger emulsification performance [21]. Transcutol ${ }^{\circledR} \mathrm{P}$ has a hydrophiliclipophilic balance (HLB) of 4.2, as a lipophilic surfactant, while PEG 400, Kolliphor ${ }^{\circledR}$ EL, and Tween 80 have HLB values of $11.3,13.5$, and 15 , respectively, all of which are hydrophilic surfactants $[22,23]$. Although the HLB value for Transcutol ${ }^{\circledR} \mathrm{P}$ was smaller than that for PEG 400, the combination of Transcutol ${ }^{\circledR} \mathrm{P}$ and Kolliphor ${ }^{\circledR}$ EL can better adjust the HLB value of the system, more effectively 

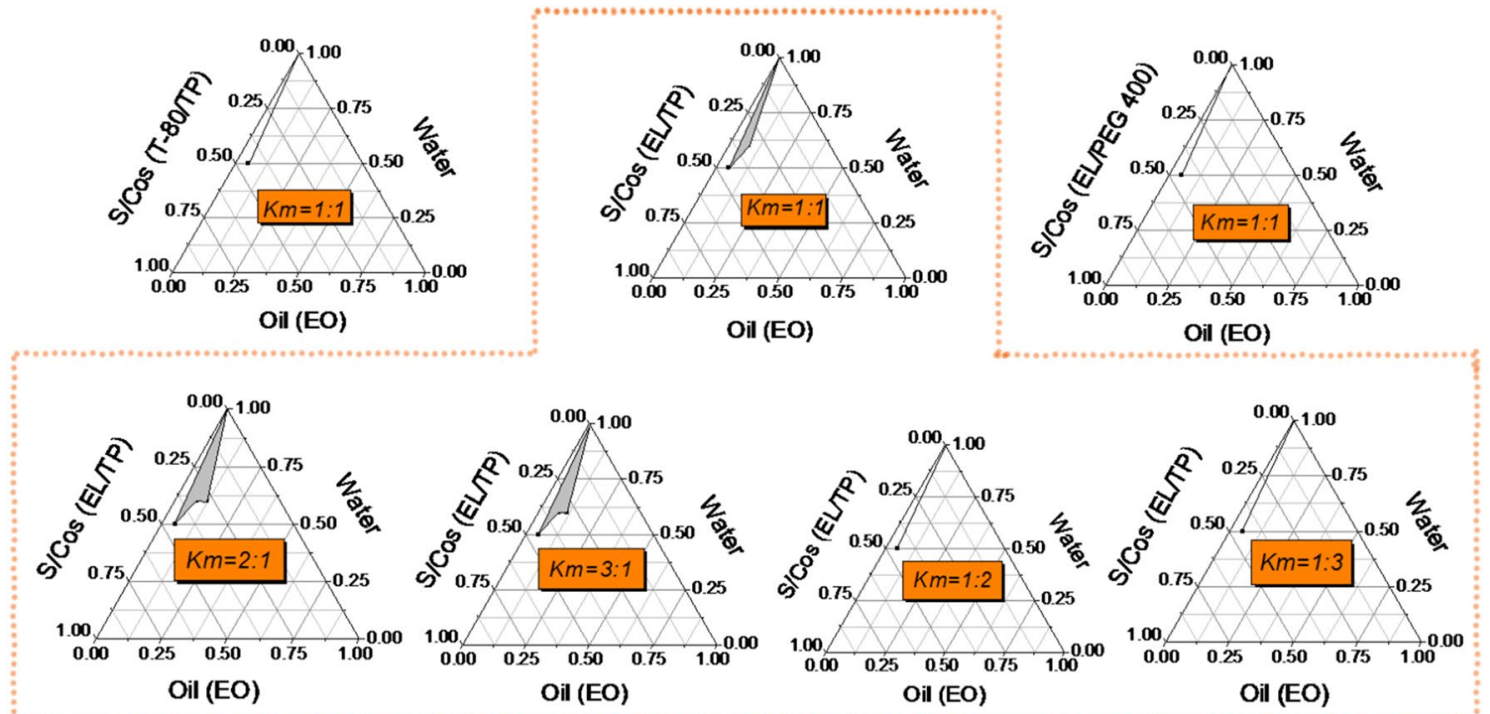

Fig. 1 Pseudo-ternary phase diagram with Tween 80 (T-80) and Kolliphor ${ }^{\circledR}$ EL (EL) as surfactants (S), Transcutol ${ }^{\circledR}$ P (TP) and PEG 400 as co-surfactants (COS), and ethyl oleate (EO) as the oil phase (Oil). Km is the mass ratio of the surfactant to co-surfactant, and the shaded area in the diagram is the oil in water $(\mathrm{O} / \mathrm{W})$ microemulsion region

reducing tension and enhancing flexibility at the oilwater interface to obtain a larger microemulsion region.

Kolliphor $^{\circledR}$ EL and Transcutol ${ }^{\circledR} \mathrm{P}$ were selected as mixed surfactants, and ethyl oleate was used as the oil phase to prepare the microemulsion. As the Km value decreased, the microemulsion region decreased. When $\mathrm{Km}$ was less than $1: 1$, it was difficult to obtain the microemulsion; it is possible that the greater amount of Transcutol ${ }^{\circledR} \mathrm{P}$ than Kolliphor ${ }^{\circledR}$ EL sharply decreased the HLB value of the system and weakened the emulsification ability, thus making it difficult to effectively reduce the oil-water interfacial tension. When the $\mathrm{Km}$ value was greater than $2: 1$, there was no significant increase in the microemulsion-forming region, indicating that excess surfactant does not significantly increase microemulsion production.

The freezing points of the microemulsions prepared with different $\mathrm{Km}$ values decreased as the amount of Kolliphor ${ }^{\circledR}$ EL increased (Fig. 2a). To use less surfactant and to prepare a microemulsion with a lower freezing point, Kolliphor ${ }^{\circledR}$ EL and Transcutol ${ }^{\circledR} \mathrm{P}$ with a Km value of $1: 1$ and a weight ratio of the mixed surfactant to the oil phase of 9:1 were used to prepare the novel perfusate. The freezing point of the microemulsion decreased by dilution with Ringer's solution (Fig. 2b). When the volume ratio of the microemulsion to Ringer's solution was $1: 6$, the freezing point of the system was $-0.51 \pm 0.02{ }^{\circ} \mathrm{C}$, which was close to the freezing point of plasma $\left(-0.52{ }^{\circ} \mathrm{C}\right)$.
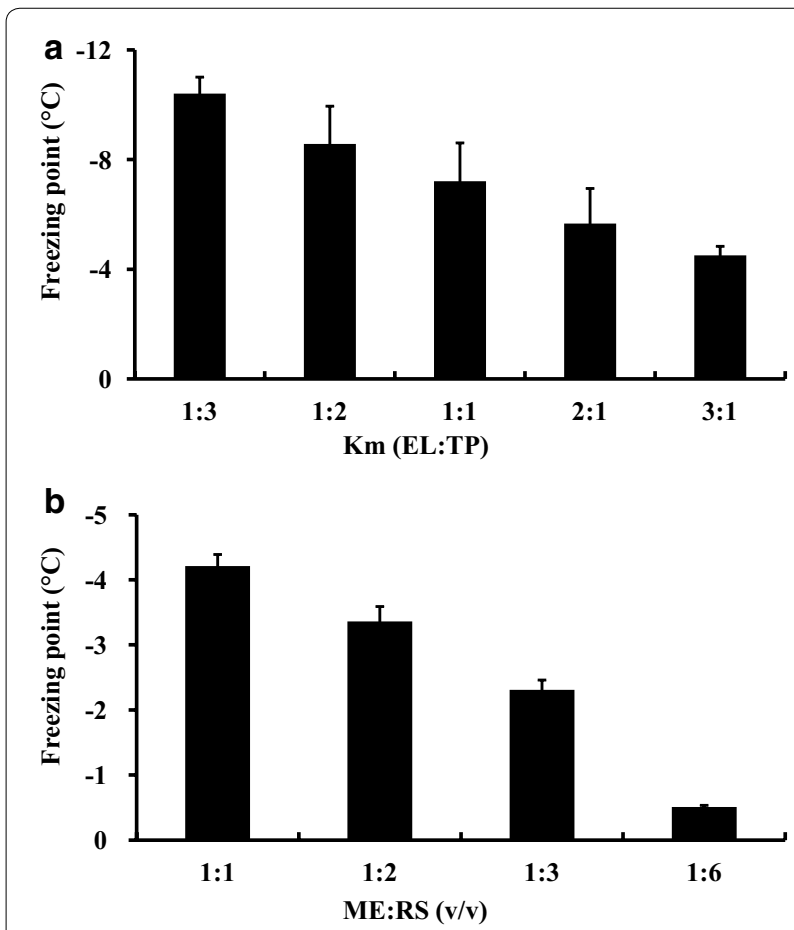

Fig. 2 Freezing point of the microemulsion prepared using Kolliphor $^{\circledR}$ EL (EL) as the surfactant (S) and Transcuto ${ }^{\circledR} \mathrm{P}(\mathrm{TP})$ as the co-surfactant with different $\mathrm{Km}$ (EL/TP, w/W) values (a), and dilution of the microemulsion (ME) with various volumes of Ringer's solution (RS) (b) 
The newly prepared perfusate (microemulsion/Ringer's solution $=1: 6, \mathrm{v} / \mathrm{v}$ ) was characterized by a mean droplet size of $78.3 \pm 1.2 \mathrm{~nm}$ (Fig. 3a) and a zeta potential of $-3.5 \pm 0.1 \mathrm{mV}$. Electrostatic repulsion delays coalescence, flocculation of the suspensions, and phase separation; this is why zeta potential is often considered an indicator of microemulsion stability. It is generally believed that the system is stable when the absolute value of zeta potential is greater than $30 \mathrm{mV}$, but zeta potential does not fully reflect the stability of the microemulsion. For microemulsion systems containing nonionic surfactants, steric hindrance plays an important role in stability. The stability of microemulsions with a low absolute value of zeta potential is still good, consistent with our findings [24]. The RS-ME was physicochemically stable after storage at $25{ }^{\circ} \mathrm{C}$ for 1 month, as evidenced by the lack of differences respectively in microemulsion droplet size distribution and zeta potential between 0 and 1 month $(\mathrm{p}>0.05)$ (Fig. 3b). In addition, centrifugation indicated no delamination of the RS-ME, indicating that the novel perfusate possessed good physical stability.

The microemulsion was spherical in shape and was evenly distributed without adhesion in the TEM field; droplets were broken by the addition of DMSO (Fig. 3c). The $\mathrm{pH}$ value of the novel perfusate was $6.2 \pm 0.6$. The viscosity of RS-ME was greater than that of Ringer's solution but significantly lower than that of 20\% PEG 400 Ringer's solution $(\mathrm{p}<0.01)$ (Fig. 3d), suggesting better fluidity. The lower viscosity of RS-ME may facilitate the diffusion of analyte molecules around the dialysis membrane into to the perfusate during microdialysis.

\section{Microdialysis}

Microdialysis is a reliable tool for monitoring endogenous and exogenous substances in the fluids of almost every tissue and organ in vivo [25]. Probe recovery is an important property of microdialysis systems [26]. Assuming that the perfusate can effectively dissolve the analyte, probe recovery mainly depends on the perfusate flow in the microdialysis probe [27]. When the perfusate flow is slow, analyte diffusion between the probe and the tissue fluid is closer to equilibrium, leading to a higher recovery rate. However, when the perfusate flow rate is too low, an insufficient amount of dialysate is collected for determination during the sampling interval. Therefore, a suitable perfusion flow should maximize probe recovery and ensure an adequate volume of dialysate for detection [28]. The flow rate is usually set to $0.1-5 \mu \mathrm{L} /$ min. Additionally, the perfusate flow should not exceed $5-10 \mu \mathrm{L} / \mathrm{min}$ because the outflow of perfusate with high pressure may cause tissue damage and insufficient material exchange on both sides of the dialysis membrane.
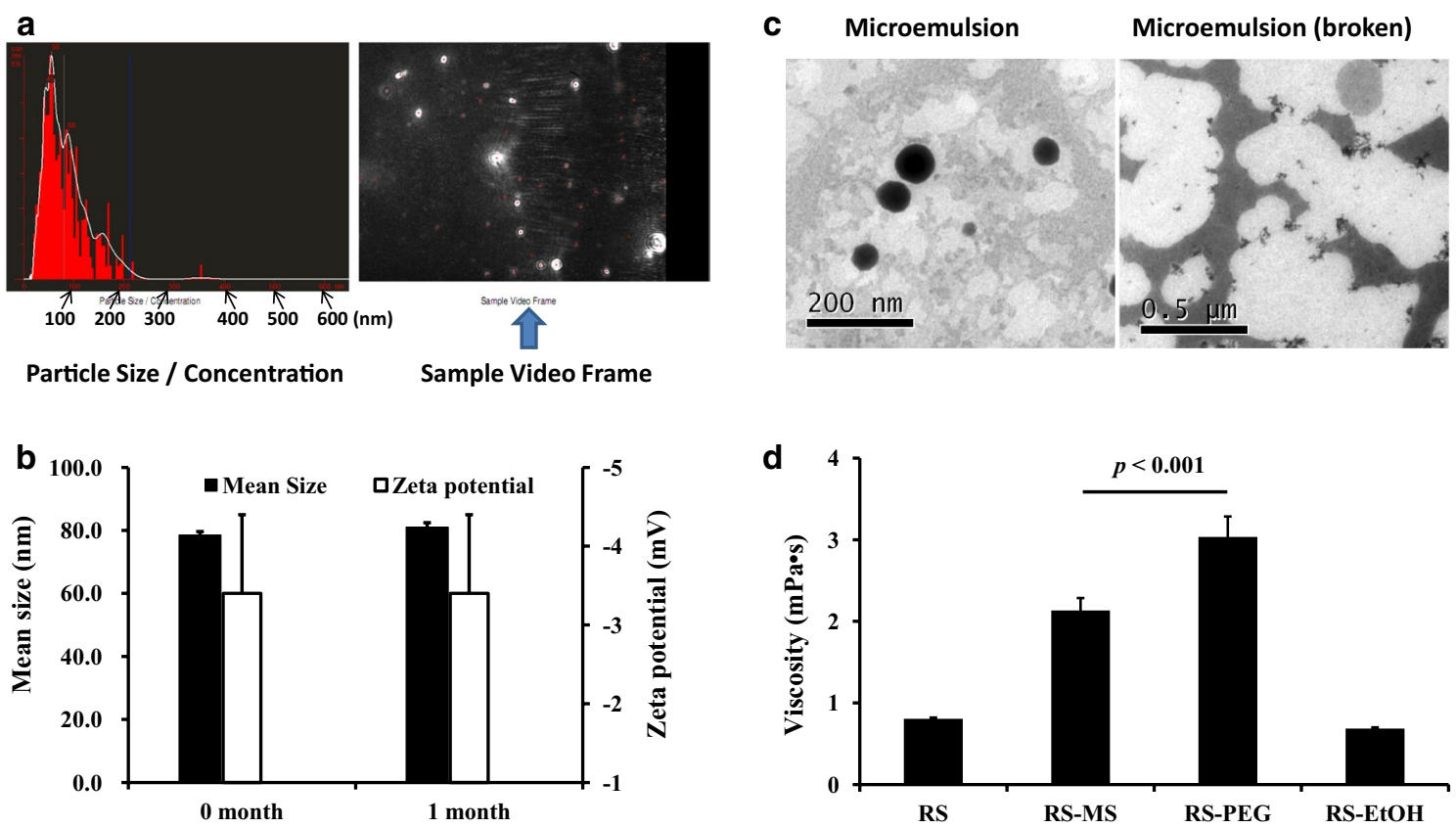

Fig. 3 Characteristics of the Ringer's solution-adjusted microemulsion-based isotonic perfusate (RS-ME), including droplet size distribution, as determined by NanoSight detection (a), the mean size and zeta potential of the RS-ME after storage for 0 and 1 month at $25^{\circ} \mathrm{C}(\mathbf{b})$, transmission electron microscope imaging of the RS-ME (microemulsion) and its demulsification state after adding dimethyl sulfoxide (c), and the viscosity of the perfusate at $25^{\circ} \mathrm{C}$ (RS, Ringer's solution; RS-PEG, 20\% [v/v] PEG 400 Ringer's solution; RS-EtOH, 10\% [v/v] ethanol Ringer's solution) (d) 

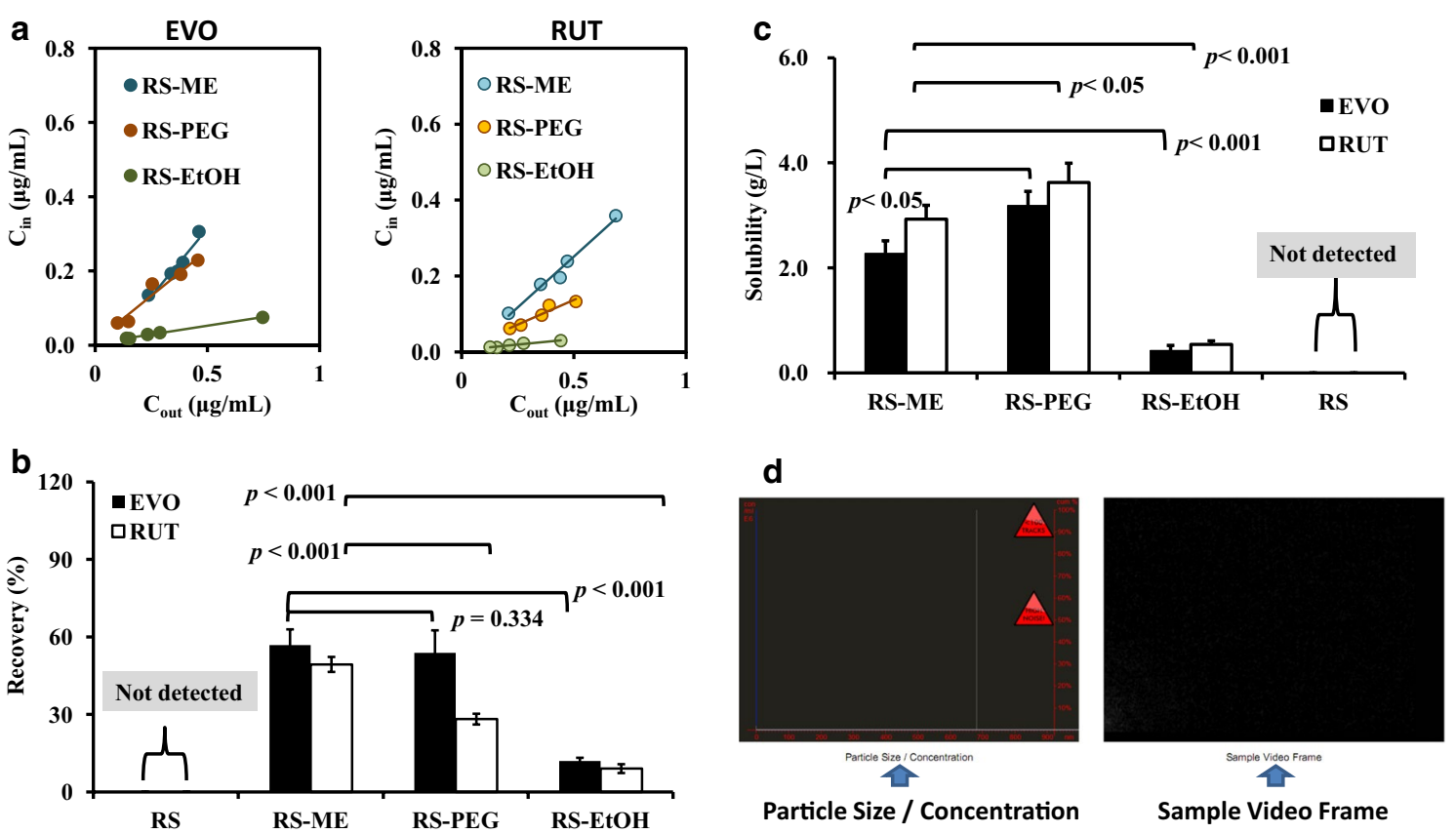

Fig. 4 In vitro microdialysis and solubility analyses. Linear curve of the drug concentration in the dialysate $\left(C_{\text {in }}\right)$ against the drug concentration in the medium outside of the probe membrane $\left(\mathrm{C}_{\text {out }}\right)(\mathbf{a})$, microdialysis probe recoveries of evodiamine $(E V O)$ and rutaecarpine (RUT) using different perfusates (RS, Ringer's solution; RS-ME, Ringer's solution-adjusted microemulsion-based isotonic perfusate; RS-PEG, 20\% [V/V] PEG 400 Ringer's solution; RS-EtOH, $10 \%\left[\mathrm{v} / \mathrm{v}\right.$ ] ethanol Ringer's solution) (b), solubility of EVO and RUT in the perfusates at $25^{\circ} \mathrm{C}(\mathbf{c})$, and NanoSight tracking analysis of the medium treated with the microdialysis probe dialyzed by RS-ME for $10 \mathrm{~h}$ (d)

Table 1 Summary of regression equations for the drug concentration in the dialysate $\left(C_{i n}\right)$ against the drug concentration in the medium outside of the probe membrane $\left(C_{\text {out }}\right)$

\begin{tabular}{lllll}
\hline Dialysate & \multicolumn{4}{l}{ Regression parameters } \\
\cline { 2 - 5 } & EVO & $\boldsymbol{R}^{\mathbf{2}}$ & RUT & $\boldsymbol{R}^{\mathbf{2}}$ \\
\hline RS & $C_{\text {in }}=0$ & - & $C_{\text {in }}=0$ & - \\
RS-ME & $C_{\text {in }}=0.731 C_{\text {out }}-0.051$ & 0.936 & $C_{\text {in }}=0.535 C_{\text {out }}-0.016$ & 0.981 \\
RS-PEG & $C_{\text {in }}=0.489 C_{\text {out }}+0.010$ & 0.942 & $C_{\text {in }}=0.261 C_{\text {out }}+0.006$ & 0.926 \\
RS-EtOH & $C_{\text {in }}=0.093 C_{\text {out }}+0.005$ & 0.996 & $C_{\text {in }}=0.058 C_{\text {out }}+0.005$ & 0.957 \\
\hline
\end{tabular}

EVO, evodiamine; RUT, rutaecarpine; RS, Ringer's solution; RS-ME, Ringer's solution-adjusted microemulsion-based isotonic perfusate; RS-PEG, $20 \%(\mathrm{v} / \mathrm{v})$ PEG 400 Ringer's solution; RS-EtOH, 10\% (v/v) ethanol Ringer's solution

In a previous study, we confirmed that EVO and RUT recovery and delivery were equal at a perfusate flow of $0.2 \mathrm{~mL} / \mathrm{h}(3.33 \mu \mathrm{L} / \mathrm{min})$, and sufficient dialysate for HPLC analysis could be obtained within $30 \mathrm{~min}$ [17]. In this study, RS-ME, 20\% PEG 400 Ringer's solution (RS-PEG), 10\% ethanol Ringer's solution (RS-EtOH), and Ringer's solution (RS) were used as perfusates. As shown in Fig. 4a, as the drug outside the probe increased, the drug in the corresponding perfusate increased, indicating a good linear relationship $\left(R^{2}>0.9\right.$; Table 1), suggesting that probe recovery is not highly affected by changes in the peripheral drug concentration. The highest drug concentration was captured in the RS-ME, followed by RS-PEG and RS-EtOH, while no EVO or RUT in RS could be detected by HPLC. The recovery of EVO and RUT using the RS-ME was significantly greater than that of the perfusate used for comparison ( $<<0.001)$ (Fig. 4b). The solubilities of EVO and RUT in the RS-ME were both lower than those in the RS-PEG $(\mathrm{p}<0.05)$; both of the ingredients showed the lowest solubilities in RS-EtOH $(\mathrm{p}<0.001)$, except for RS (with levels below the HPLC detection limits for EVO and RUT) (Fig. 4c). The lower viscosity of RS-ME than RS-PEG allows the drug molecules to diffuse more easily across the microdialysis membrane, thus contributing to greater recovery. After dialysis for $10 \mathrm{~h}$ using the RS-ME as a perfusate, no nano-scale droplets were found in the medium outside of the dialysis membrane (Fig. 4d), indicating that the droplets in the RS-ME were stable and retained by the dialysis membrane to avoid diffusion outside of the probe. However, PEG400 and ethanol molecules dispersed in the RS-PEG and RS-EtOH may diffuse through the dialysis membrane, reducing the stability of the perfusate and affecting the 

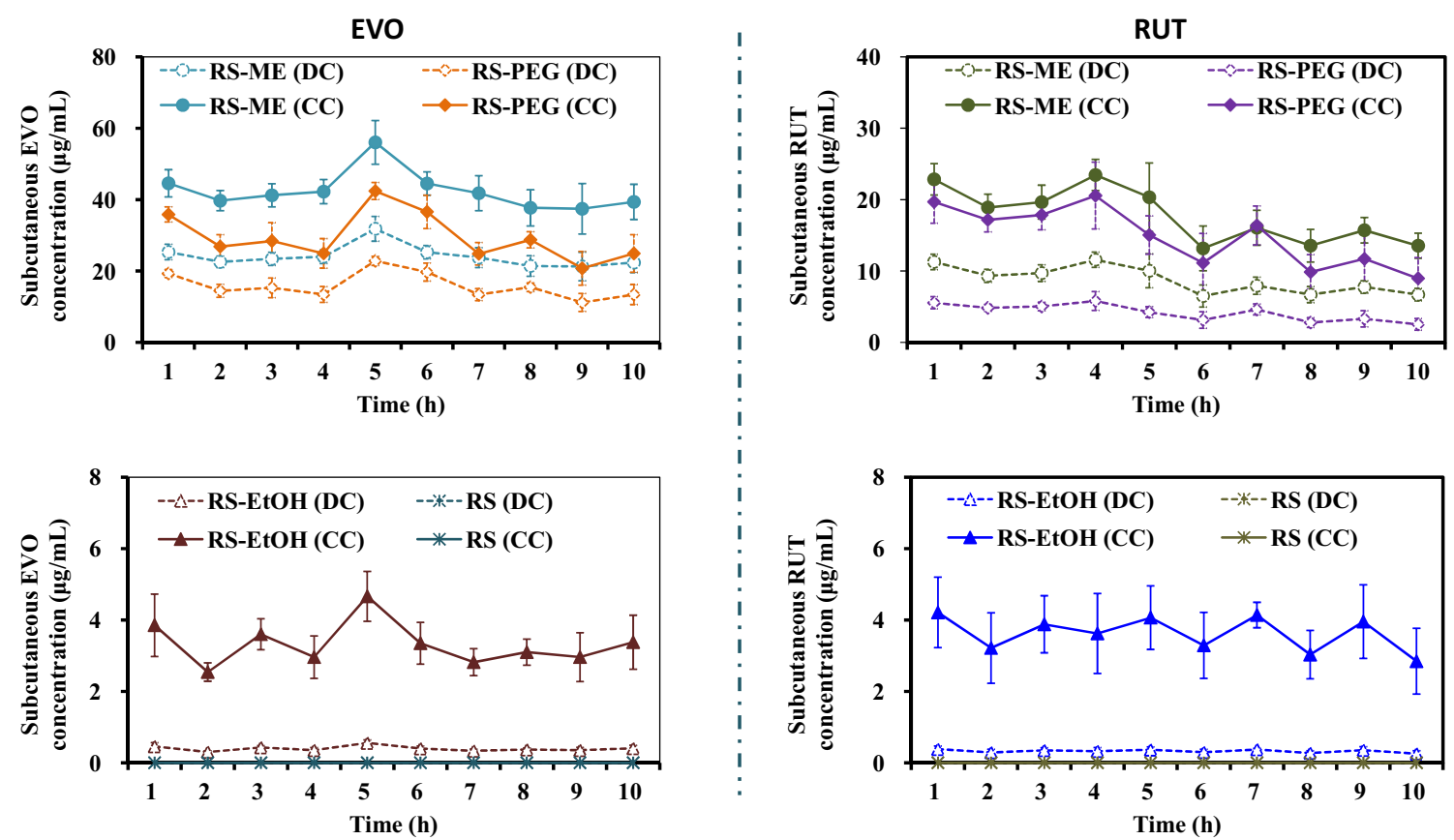

Fig. 5 Evodiamine (EVO) and rutaecarpine (RUT) concentrations in the dialysate samples from rat subcutaneous tissues over time (DC, drug concentration by direct detection; CC, drug concentration determined by microdialysis probe recovery) based on in vivo microdialysis using various perfusates (RS, Ringer's solution; RS-ME, Ringer's solution adjusted microemulsion-based isotonic perfusate; RS-PEG, 20\% [V/v] PEG 400 Ringer's solution; RS-EtOH, 10\% [v/v] ethanol Ringer's solution)

tissue microenvironment and drug distribution surrounding the probe, further increasing the error of the experiment.

The in vivo microdialysis results showed that greater EVO and RUT were obtained using the RS-ME as the perfusate than using RS-PEG and RS-EtOH, while the drug molecules could not be detected in the dialysis samples from the RS group (Fig. 5). After recovery, fluctuations in the concentrations of EVO and RUT in subcutaneous tissues were the same as those observed by direct detection. These results show that RS-ME enables superior dialysis of fat-soluble drug molecules and has good fluidity and stability, resulting in better performance than that of the other perfusates.

After $10 \mathrm{~h}$ of microdialysis, compared with the untreated dialysis membrane, the microdialysis membranes treated with RS-ME, RS-PEG, and RS-EtOH all showed better toughness; the inner and outer surfaces remained smooth and the cross sections showed no obvious structural changes (Fig. 6). The dialysis membrane tolerated the tested perfusate well, thus ensuring the reliability of the experimental results.

\section{Biocompatibility}

In skin microdialysis experiments, probes are usually embedded in subcutaneous tissues. Fibroblasts are the main cells in subcutaneous connective tissues. To further evaluate the safety of the perfusates, human embryonic skin fibroblasts (CCC-ESF-1) were cultured in vitro, and the perfusates were directly added to the cells for incubation. After pyridine iodide staining, dead cells emit strong red fluorescence at $660 \mathrm{~nm}$, and dead cells can be distinguished from living cells by flow cytometry (FCM). After incubation for $24 \mathrm{~h}$, cells showed normal morphology with few dead and suspended cells in the RS group; however, cells in the RS-ME and RS-PEG groups exhibited slight shrinkage with some cell death. The RS-EtOH group had more cell death (Fig. 7a). Figure 7b shows representative FCM scatter plots. Living cells in all groups exceeded $80 \%$, except in the RS-EtOH group (Fig. 7c), suggesting that RS-ME and RS-PEG had good biocompatibility with cells at the tested concentrations.

During microdialysis, components of the perfusate may diffuse through the dialysis membrane into the tissue. Based on a hemolytic assay, the hemolytic activity of the perfusate released through the dialysis membrane was very low and did not cause acute hemolysis according to ISO/TR7405-1984 (E) [29]. Notably, the hemolysis rate of the RS-ME group was significantly lower $(\mathrm{p}<0.001)$ than those for the RS-PEG and RS-EtOH groups (Fig. 8a). RS-ME components were present in the form of droplets 

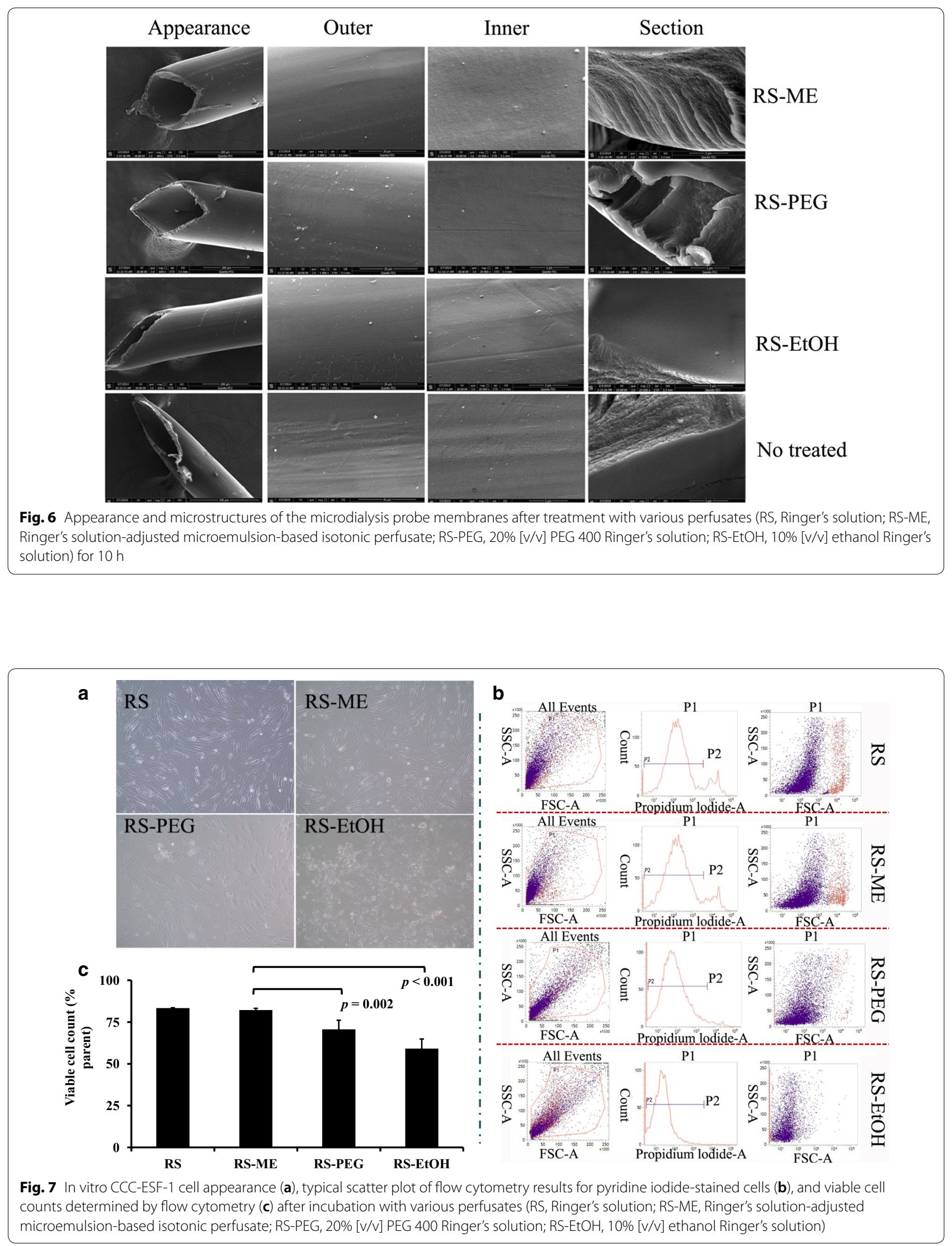


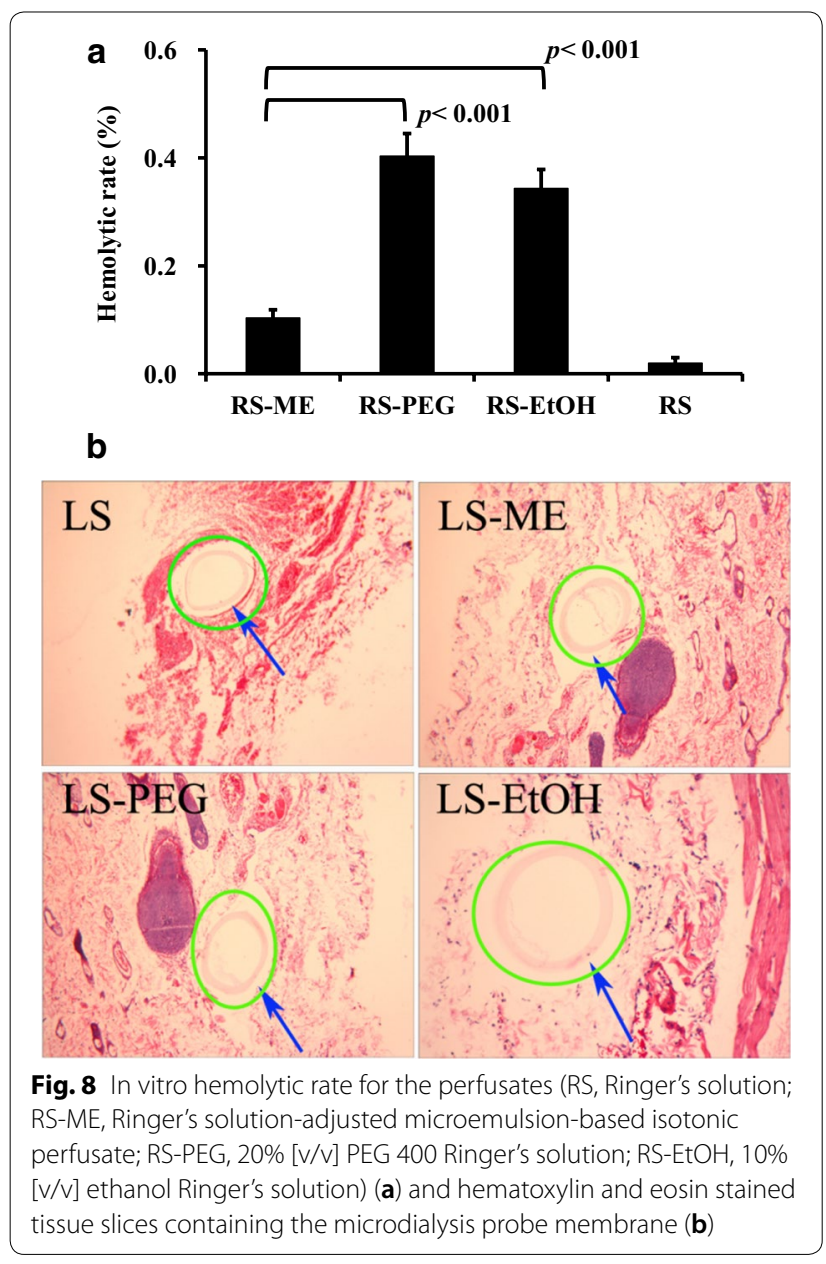

that do not easily penetrate the dialysis membrane, conferring better safety to the tissues around the probe.

After $10 \mathrm{~h}$ of microdialysis, no obvious inflammation and blood stasis were found in the skin around the dialysis membranes (Fig. 8b), indicating that the dialysis membranes had good biological safety and the perfusate had no effect on the surrounding tissues.

\section{Conclusions}

The novel perfusate prepared by microemulsion substantially improved the microdialysis probe recovery of fat-soluble ingredients compared with existing perfusates and had good biocompatibility and physicochemical stability. It resolves the limited microdialysis recovery of poorly soluble lipid ingredients using a cutaneous perfusate. The microemulsion-based novel perfusate reduces the dependence on ultra-high sensitivity detection techniques, such as multi-stage mass spectrometry, in microdialysis experiments by substantially increasing the probe recovery of fat-soluble components, making it possible to use common detection methods, such as HPLC, thereby extending the practical applications of microdialysis technology.

\section{Methods \\ Materials}

EVO and RUT (purity 98\%) were supplied by Linuo Biotechnology Co., Ltd. (Zhengzhou, China). Diethylene glycol monoethyl ether (Transcutol ${ }^{\circledR} \mathrm{P}$ ) was obtained from Gattefossé (Lyon, France). Polyethylene glycol (PEG)-35 castor oil (Kolliphor ${ }^{\circledR}$ EL) was a gift from BASF (Ludwigshafen, Germany). Ringer's solution was purchased from Minsheng Pharma (Hangzhou, China). The materials used for in vitro cell studies were all obtained from Shanghai Usen Biotechnology (Shanghai, China). All other chemicals were obtained from Sinopharm Chemical Reagent Co. Ltd. (Shanghai, China) and were of high performance liquid chromatography (HPLC) or analytical grade.

\section{Animals and cell line}

Male Sprague-Dawley rats weighing 180-220 g were used. The animal study was approved by the Animal Ethical Committee, Shanghai University of Traditional Chinese Medicine, by holding the Laboratory Animal Use License (SYXK $[\mathrm{Hu}]$ 2014-0008) issued by the Shanghai Science and Technology Commission.

Human embryonic skin fibroblasts (CCC-ESF-1) were obtained from the Shanghai Institute of Biochemistry and Cell Biology (Shanghai, China).

\section{HPLC assay}

The LC-2010A HT Liquid Chromatography System (Shimadzu Corporation, Kyoto, Japan) was used to detect Evo and Rut with a C18 reverse phase column $(5 \mu \mathrm{m}, 4.6 \mathrm{~mm}$ inner diameter $\times 25 \mathrm{~cm}$ ). The mobile phase was acetonitr ile:water:tetrahydrofuran:acetic acid (41:59:1:0.2, v/v/v/v) with a flow rate of $1 \mathrm{~mL} / \mathrm{min}$ with a detection wavelength of $225 \mathrm{~nm}$. The intra-day and inter-day relative standard deviations were $1.21 \%$ and $1.57 \%$ for Evo and $1.30 \%$ and $2.24 \%$ for Rut, respectively. The microdialysis samples using the microemulsion as a perfusate were tested after adding dimethyl sulfoxide (DMSO) to break the emulsion and the perfusate not formulated with ME were assayed in a timely manner, without any handling.

\section{Preparation of the $\mathrm{O} / \mathrm{W}$ microemulsion}

The microemulsion was prepared using the water titration method at $25^{\circ} \mathrm{C}$. Briefly, the ethyl oleate, surfactant, and cosurfactant were mixed, then water was added dropwise with magnetic stirring at $300 \mathrm{rpm}$. The system may occur as different states; the microemulsion was clear, transparent, and low in viscosity, the ordinary emulsion exhibited an opaque and turbid milky white 
state, and a viscous, non-flowing gel state was observed after tilting.

\section{Preparation and characterizations of the novel perfusate} The microemulsion-based isotonic perfusate was formulated by diluting ME in Ringer's solution. The Ringer's solution ME-based perfusate (RS-ME) was observed using a transmission electron microscope (TEM) (Philips Tecnai 12; Philips, Amsterdam, the Netherlands) as follows. Samples were dropped onto copper nets and dried for $20 \mathrm{~min}$, followed by negative staining with $2 \%$ phosphotungstic acid. Samples were allowed to dry for $10 \mathrm{~min}$ and observed by TEM. The freezing point of the solutions was determined using a freezing point osmometer (BS100; Yida Medical Devices Co., Ltd., Hangzhou, China). The viscosities of the formulations were measured using a DV-I + Digital Viscometer (Brookfield Engineering Laboratories Inc., Middleborough, MA, USA) with the No. 1 rotor set to $100 \mathrm{rpm}$, and the $\mathrm{pH}$ values were determined using a Jenway Digital $\mathrm{pH}$ Meter (Bibby Scientific Limited, Stone, UK) at $25^{\circ} \mathrm{C}$. The size distribution of the ME droplets in the prepared perfusate was determined using the NanoSight LM10 (Malvern Panalytical, Worcestershire, UK).

The 10\% (v/v) ethanol Ringer's solution (RS-EtOH) and $20 \%(\mathrm{v} / \mathrm{v})$ polyethylene glycol (PEG) 400 Ringer's solution (RS-PEG) were prepared for comparison.

\section{Stability of RS-ME}

The RS-ME was stored at $25^{\circ} \mathrm{C}$ for 1 month, and its physical stability was evaluated by observations of phase separation and droplet size changes, and by a centrifugation stability test at 10,000 rpm for $30 \mathrm{~min}$.

\section{Solubility of EVO and RUT}

Excess EVO and RUT were added separately to different solvents, shaken at $25 \pm 1{ }^{\circ} \mathrm{C}$ for $48 \mathrm{~h}$, and centrifuged at $30,000 \times g$ for $30 \mathrm{~min}$. The supernatant was diluted with methanol, and the concentration of the drug in the saturated solution was determined by HPLC.

\section{Microdialysis}

A linear microdialysis probe with a length of $2 \mathrm{~cm}$ and a hollow fiber membrane (13,000 Da molecular weight cut-off, Spectra/Por ${ }^{\circledR}$; Spectrum Laboratories Inc., Rancho Dominguez, CA, USA) was used, and perfusion with a flow rate of $0.2 \mathrm{~mL} / \mathrm{h}$ was conducted using a microinfusion pump (WZ-50C6; Smiths Medical, Southington, CT, USA). Recovery validation and in vivo microdialysis sampling methods were conducted in accordance with our previous reports. Briefly, the linear probe was placed in EVO or RUT aqueous solutions with different concentrations, and dialysis was performed using the perfusates.
The equilibration period was $30 \mathrm{~min}$, and the dialysate was then collected for $30 \mathrm{~min}$. The drug concentrations in the dialysate $\left(\mathrm{C}_{\mathrm{d}}\right)$ and medium $\left(\mathrm{C}_{\mathrm{m}}\right)$ were determined by HPLC. The recovery was calculated according to Eq. 1 [30].

$$
\text { Recovery }(\%)=\left(C_{d} / C_{m}\right) \times 100
$$

For in vivo microdialysis studies, the hair on the abdominal region of an anaesthetized rat was shaved and the probe was implanted in the skin. The donor cell was stuck to the skin above the probe, and $1 \mathrm{~mL}$ of the EVO or RUT ethanol solution (EVO or RUT dissolved in 70\% ethanol at concentrations of $0.2 \mathrm{mg} / \mathrm{mL}$ ) was applied to the skin with a contact area of $1 \mathrm{~cm}^{2}$. Perfusion was first started for $1 \mathrm{~h}$ for equilibrium, then the drug was applied. Dialysate samples were collected every 30 min for $10 \mathrm{~h}$ and were assayed directly by HPLC.

\section{Structure of the probe membrane}

After the microdialysis process, part of the dialysis membrane was cut off and washed with distilled water, followed by $\mathrm{CO}_{2}$ critical point drying and platinum sputtering. Images were obtained by scanning electron microscopy (Quanta FEG250; FEI, Hillsboro, OR, USA).

\section{In vitro cytotoxicity}

CCC-ESF cells in a six-well culture dish at $5 \times 10^{5}$ cells/ well were incubated at $37^{\circ} \mathrm{C}$ with $5 \% \mathrm{CO}_{2}$ for $12 \mathrm{~h}$. Then, $200 \mu \mathrm{L}$ of medium was removed from each well and replaced with $200 \mu \mathrm{L}$ of the tested solutions. After incubation for $24 \mathrm{~h}\left(37^{\circ} \mathrm{C}, 5 \% \mathrm{CO}_{2}\right)$, the cells were collected, resuspended in PBS, sonicated at $20 \mathrm{kHz}$ for $10 \mathrm{~s}$, and treated with propidium iodide aqueous solution $(1 \mathrm{mg} /$ $\mathrm{mL}$ ) for $5 \mathrm{~min}$. Samples were assayed using a flow cytometer (Becton-Dickinson and Company, Canaan, CT, USA).

\section{Hemolysis test}

Fibrin in fresh rat blood was removed, diluted with a tenfold volume of normal saline, and centrifuged at $250 \times g$ for $5 \mathrm{~min}$. The precipitated red blood cells were collected and washed 3 times with normal saline. The red blood cells were formulated into a $2 \%$ suspension $(\mathrm{v} / \mathrm{v})$ with normal saline. One milliliter of the cell suspension was placed in an infusion tube to simulate blood vessels. The microdialysis probe was implanted into the red blood cell suspension in the infusion tube (internal diameter: $2 \mathrm{~mm}$ ) and perfused with the prepared novel perfusate for $2 \mathrm{~h}$. At the end of the experiment, the red blood cell suspension was removed and centrifuged at $250 \times g$ for $5 \mathrm{~min}$. The supernatant was obtained after centrifugation from red blood cells and diluted in a $2 \%$ suspension with normal saline and distilled water as negative and positive controls. The absorption (A) 
of the supernatant collected from the novel perfusate samples (NP) and negative (NC) and positive (PC) controls was measured using an ultraviolet spectrophotometer (UV765; Shanghai Jingmi Scientific instruments Co., Ltd., Shanghai, China) at a wavelength of $540 \mathrm{~nm}$. The hemolysis rate (HR) was calculated according to Eq. 2 [31].

$$
\operatorname{HR}(\%)=\frac{\left(\mathrm{A}_{\mathrm{NP}}-\mathrm{A}_{\mathrm{NC}}\right)}{\left(\mathrm{A}_{\mathrm{PC}}-\mathrm{A}_{\mathrm{NC}}\right)} \times 100
$$

\section{Dermal irritation}

Rats were sacrificed after microdialysis was completed. The drug was removed from the skin, and the skin was excised, washed with normal saline, and fixed in $4 \%(\mathrm{w} / \mathrm{v})$ polyoxymethylene for $48 \mathrm{~h}$. Skins slices were embedded in paraffin and stained with hematoxylin and eosin. An optical microscope (BH-2; Olympus Corporation, Hatagaya, Japan) was used to observe skin tissues.

\section{Data analysis}

Data are presented as mean values \pm standard deviation. Significant differences were evaluated by Student's $t$-tests, with $\mathrm{p}<0.05$ indicating significance.

\section{Authors' contributions}

YT, Z and LN mainly completed the whole project and drafted the manuscript. YY, ZH and Q helped conduct the cell culture. NP supervised the entire project and assisted in the analysis of data. All authors read and approved the final manuscript.

\section{Acknowledgements}

This work was financially supported by the National Natural Science Foundation of China (81673612, 81573619). English-language editing was provided by Editage (Cactus Communications Inc.).

\section{Competing interests}

The authors declare that they have no competing interests.

\section{Data sharing}

All data generated or analyzed during this study are included in this published article.

\section{Ethics approval and consent to participate}

Not applicable.

\section{Funding}

This work was supported by the National Natural Science Foundation of China (81673612, 81573619, 81303234), which aided in the design and analysis of this study.

\section{Publisher's Note}

Springer Nature remains neutral with regard to jurisdictional claims in published maps and institutional affiliations.

Received: 16 September 2018 Accepted: 2 November 2018

Published online: 14 November 2018

\section{References}

1. Hammarlund-Udenaes M. Microdialysis as an important technique in systems pharmacology — a historical and methodological review. AAPS J. 2017;19:1294-303.

2. Bongaerts J, De Bundel D, Mangelings D, Smolders I, Vander Heyden Y, Van Eeckhaut A. Sensitive targeted methods for brain metabolomic studies in microdialysis samples. J Pharm Biomed Anal. 2018;161:192-205.

3. Kaplan E, Zubedat S, Radzishevsky I, Valenta AC, Rechnitz O, Sason H, et al. ASCT1 (SIC1a4) transporter is a physiologic regulator of brain D-serine and neurodevelopment. Proc Natl Acad Sci USA. 2018. https://doi. org/10.1073/pnas.1722677115.

4. Estrade L, Cassel JC, Parrot S, Duchamp-Viret P, Ferry B. Microdialysis unveils the role of the a2-adrenergic system in the basolateral amygdala during acquisition of conditioned odor aversion in the rat. ACS Chem Neurosci. 2018. https://doi.org/10.1021/acschemneuro.8b00314.

5. Yang H, Li T, Liu L, Li N, Guan M, Zhang Y, et al. Metal-organic frameworks as affinity agents to enhance the microdialysis sampling efficiency of fatty acids. Analyst. 2018;143:2157-64.

6. Fletcher HJ, Stenken JA. An in vitro comparison of microdialysis relative recovery of Met- and Leu-enkephalin using cyclodextrins and antibodies as affinity agents. Anal Chim Acta. 2008;620:170-5.

7. Duo J, Fletcher H, Stenken JA. Natural and synthetic affinity agents as microdialysis sampling mass transport enhancers: current progress and future perspectives. Biosens Bioelectron. 2006;22:449-57.

8. Smith CJ, Craighead DH, Alexander LM. Effects of vehicle microdialysis solutions on cutaneous vascular responses to local heating. J Appl Physiol. 1985;2017(123):1461-7.

9. Prévost S, Gradzielski M, Zemb T. Self-assembly, phase behavior and structural behavior as observed by scattering for classical and non-classical microemulsions. Adv Colloid Interface Sci. 2017;247:374-96.

10. Cerpnjak K, Zvonar A, Gašperlin M, Vrečer F. Lipid-based systems as a promising approach for enhancing the bioavailability of poorly watersoluble drugs. Acta Pharm. 2013;63:427-45.

11. Zhai Y, Zhai G. Advances in lipid-based colloid systems as drug carrier for topic delivery. J Control Release. 2014;193:90-9.

12. Amiri-Rigi A, Abbasi S. Microemulsion-based lycopene extraction: effect of surfactants, co-surfactants and pretreatments. Food Chem. 2016;197:1002-7.

13. Liu XY, Niu X, Feng QJ, Yang XZ, Wang DW, Zhao T, et al. A new biocompatible microemulsion increases extraction yield and bioavailability of Andrographis paniculata. Chin J Nat Med. 2016;14:683-91.

14. Oberdisse J, Hellweg T. Structure, interfacial film properties, and thermal fluctuations of microemulsions as seen by scattering experiments. Adv Colloid Interface Sci. 2017;247:354-62.

15. Xing Q, Song J, You X, Xu D, Wang K, Song J, et al. Microemulsions containing long-chain oil ethyl oleate improve the oral bioavailability of piroxicam by increasing drug solubility and lymphatic transportation simultaneously. Int J Pharm. 2016;511:709-18.

16. Rowe RC, Sheskey PJ, Owen SC. Handbook of pharmaceutical excipients. 4th ed. London: Pharmaceutical Press; 2003.

17. Zhang YT, Zhao JH, Zhang SJ, Zhong YZ, Wang Z, Liu Y, et al. Enhanced transdermal delivery of evodiamine and rutaecarpine using microemulsion. Int J Nanomed. 2011;6:2469-82.

18. Constantinides PP. Lipid microemulsions for improving drug. Pharm Res. 1995;12:1561-72.

19. Callender SP, Mathews JA, Kobernyk K, Wettig SD. Microemulsion utility in pharmaceuticals: implications for multi-drug delivery. Int J Pharm. 2017;526:425-42.

20. Kreilgaard M, Pedersen EJ, Jaroszewski JW. NMR characterisation and transdermal drug delivery potential of microemulsion systems. J Control Release. 2000;69:421-33.

21. Bravo González RC, Huwyler J, Boess F, Walter I, Bittner B. In vitro investigation on the impact of the surface-active excipients Cremophor EL, Tween 80 and Solutol HS 15 on the metabolism of midazolam. Biopharm Drug Dispos. 2004;25:37-49.

22. Vargas de Oliveira EC, Carneiro ZA, De Albuquerque S, Marchetti JM. Development and evaluation of a nanoemulsion containing ursolic acid: a promising trypanocidal agent: nanoemulsion with ursolic acid against T. cruzi. AAPS Pharm Sci Tech. 2017;18:2551-60. 
23. Bali V, Ali M, Ali J. Study of surfactant combinations and development of a novel nanoemulsion for minimising variations in bioavailability of ezetimibe. Colloids Surf B Biointerfaces. 2010;76:410-20.

24. Obitte NC, Rohan LC, Adeyeye CM, Parniak MA, Esimone CO. The utility of self-emulsifying oil formulation to improve the poor solubility of the anti HIV drug CSIC. AIDS Res Ther. 2013;10:14.

25. van der Mierden S, Savelyev SA, IntHout J, de Vries RBM, Leenaars CHC. Intracerebral microdialysis of adenosine and AMP_-a systematic review and meta-regression analysis of baseline concentrations. J Neurochem. 2018. https://doi.org/10.1111/jnc.14552.

26. Quantitative Durk MR. Intracerebral microdialysis studies to determine unbound extracellular fluid drug concentrations in discrete areas of the brain. Curr Protoc Pharmacol. 2018;80(7):pp. 18.1-19.

27. Chao YY, Wei YT, Lee CT, Kou HS, Huang YL. Membrane sampling with microdialysis coupled to HPLC/UV for on-line simultaneous determination of melamine and cyanuric acid in non-dairy coffee creamer. Anal Sci. 2011;27:1025-30.

28. Gao Q, Zhao Y, Yu J, Yang T, Ding P. Microdialysis as a tool to determine the skin concentration of mometason furoate in rats. Pharmazie. 2014;69:787-91.

29. ISO/TR7405-1984] (E). Hemolysis test (In vitro test direcdy on materials).

30. Yang M, Gu Y, Yang D, Tang X, Liu J. Development of triptolide-nanoemulsion gels for percutaneous administration: physicochemical, transport, pharmacokinetic and pharmacodynamic characteristics. J Nanobiotechnol. 2017;15:88.

31. Kaplan M, Bromiker R, Hammerman C. Hyperbilirubinemia, hemolysis, and increased bilirubin neurotoxicity. Semin Perinatol. 2014;38:429-37.
Ready to submit your research? Choose BMC and benefit from:

- fast, convenient online submission

- thorough peer review by experienced researchers in your field

- rapid publication on acceptance

- support for research data, including large and complex data types

- gold Open Access which fosters wider collaboration and increased citations

- maximum visibility for your research: over $100 \mathrm{M}$ website views per year

At BMC, research is always in progress.

Learn more biomedcentral.com/submissions 